\title{
Ureteral or vesical involvement in Henoch-Schönlein syndrome: a systematic review of the literature
}

\author{
Giordano M. Siegenthaler • Mattia Rizzi • Alberto Bettinelli • \\ Giacomo D. Simonetti • Alessandra Ferrarini • \\ Mario G. Bianchetti
}

Received: 9 May 2013 /Revised: 9 August 2013 / Accepted: 23 August 2013 /Published online: 24 September 2013

(C) IPNA 2013

\begin{abstract}
Background Little information is available on ureteral or vesical involvement in Henoch-Schönlein syndrome. To determine the features of this condition we performed a formal analysis of peer-reviewed scientific literature on this topic. Methods The US National Library of Medicine database was used as the data source. All articles published as full-length articles or letters were collected. Reports published in languages other than English, French, German, Italian or Spanish were not considered.

Results We analyzed 32 reports describing 35 cases (24 male and 11 female subjects aged between 3.5 and 63, median 7.0 years) with ureteral $(n=30)$, vesical $(n=4)$, or both ureteral and vesical involvement $(n=1)$. The presentation included colicky abdominal pain, macroscopic hematuria (sometimes containing blood clots), urinary tract infection or urinary retention. The diagnosis of ureteral involvement was often fortuitous. Patients with vesical involvement were managed conservatively. However, the majority of those with ureteral involvement were managed surgically.

Conclusions Ureteral or vesical involvement is unusual and likely underappreciated in Henoch-Schönlein syndrome.
\end{abstract}

Dr Mattia Rizzi was supported by a scholarship of the Ettore e Valeria Rossi Foundation.

G. M. Siegenthaler $\cdot$ M. Rizzi $\cdot$ A. Ferrarini $\cdot$ M. G. Bianchetti Department of Pediatrics, Mendrisio and Bellinzona Hospitals, University of Bern, Bern, Switzerland

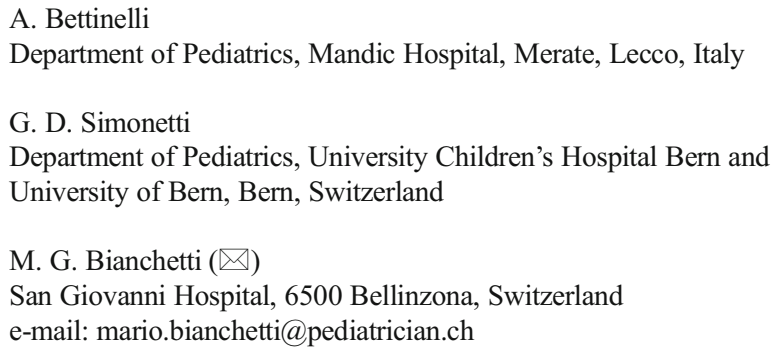

Improved recognition and wider appreciation of this involvement can help to avoid associated morbidity. Management must be individualized for each patient. A multidisciplinary approach may be of value in planning medical treatment, surgical intervention, and follow-up.

Keywords Anaphylactoid purpura $\cdot$ Henoch-Schönlein purpura $\cdot$ Systematic review $\cdot$ Ureteritis

\section{Introduction}

Henoch-Schönlein syndrome is the most common form of childhood vasculitis with an estimated overall annual incidence of 10-20 cases per 100,000 children under 17 years of age [1]. Palpable non-thrombocytopenic purpura concentrated on dependent or pressure-bearing areas, arthralgia or arthritis, and abdominal pain are the distinctive presentations of this condition [1].

The most recognized genitourinary manifestation of HenochSchönlein syndrome is a kidney disease that affects $20-60 \%$ of cases and principally determines the long-term prognosis of affected patients [1]. In addition, many boys develop scrotal signs or symptoms secondary to edema and hematoma of the scrotal wall or spermatic cord, testicular hemorrhage, subcapsular testicular hematoma, epididymitis or orchitis [1].

Ureteral or vesical involvement is uncommon. Since textbooks and recent reviews do not, or only marginally, mention this rare complication of Henoch-Schönlein syndrome, we systematically reviewed and analyzed all the available literature.

\section{Materials and methods}

Between November 2012 and April 2013 we performed a thorough computer-based search of the terms Henoch, Schönlein, Henoch-Schönlein, Schönlein-Henoch, anaphylactoid purpura, rheumatoid purpura, angiitis, vasculitis, 
hydronephrosis, ureter, ureteritis, and bladder in the US National Library of Medicine database. We used the principles established by the UK Economic and Social Research Council guidance on the conduct of narrative synthesis and on the Preferred Reporting Items for Systematic Reviews and Meta-Analyses statement (Fig. 1). For the final analysis we selected 32 reports available as a full-length article or as a letter, which included cases of ureteral or vesical involvement in Henoch-Schönlein syndrome published after 1960.

Henoch-Schönlein cases were classified as severe in the presence of a kidney disease characterized by nephrotic range proteinuria or in the presence of at least one of the following infrequent complications: muscle involvement; protein-losing enteropathy; pancreatitis; cholecystitis; intestinal infarction, perforation or stricture; altered mental status; seizures; paresis; blindness; peripheral neuropathy; pulmonary hemorrhage; carditis; uveitis. The remaining cases were classified as mild.

The two-sided Mann-Whitney-Wilcoxon test for two independent samples and the two-sided Fisher's exact test were performed for analysis. Significance was assumed when $P<0.05$.

\section{Results}

The literature retained for the final analysis included (Fig. 2) 35 Henoch-Schönlein cases ( 25 male and 10 female subjects) with ureteral [2-30] $(n=30)$, vesical [31-33] $(n=4)$, or both ureteral and vesical involvement [11] $(n=1)$. The diagnosis of HenochSchönlein syndrome was based on the classical palpable purpuric rash in the presence of at least one of the following: diffuse abdominal pain, arthritis or arthralgia, or a pathological urinalysis [1]. Biopsy findings further supported the diagnosis of Henoch-Schönlein syndrome in 13 cases: skin biopsy $(n=3)$, kidney biopsy $(n=5)$ or both skin and kidney biopsy $(n=5)$.
Ureteral or vesical involvement was recognized at between 1 week and 14 months, a median of 1 month after onset of purpura. Henoch-Schönlein syndrome was mild in the 4 cases with isolated vesical involvement (in these subjects imaging studies excluded upper tract involvement) and severe in the case with both ureteral and vesical involvement. In the 30 patients with isolated ureteral involvement the syndrome was severe in 11 and mild in the remaining 19 cases.

Ureteral involvement

The 31 Henoch-Schönlein patients with ureteral involvement consisted of 23 male and 8 female subjects aged between 3.5 and 63 years (Fig. 2). Diagnostic imaging studies disclosing the ureteral involvement were performed in 9 patients with both colicky abdominal pain and macroscopic hematuria, in 8 with colicky abdominal pain, in 4 with macroscopic hematuria (but without concurrent abdominal pain), and in 2 with a urinary tract infection. The diagnosis of ureteral involvement was fortuitous in the remaining patients (diagnostic imaging performed for other reasons, e.g., before kidney biopsy). Microscopic hematuria had been noted in the patients without macroscopic hematuria or urinary tract infection.

Forty-six of the 62 ureteral units were obstructed in the 31 patients: the obstruction was unilateral in 16 and bilateral in 15 patients (Table 1). The obstruction mostly affected the proximal ureter. A 21-year old patient [24] initially presented with a proximal obstruction of the left ureter that was followed by an ipsilateral distal obstruction 4 weeks later. Twenty-eight ureters were partially and the remaining 19 were completely obstructed (Table 2). The management was expectative, medical with corticosteroid, surgical, or both medical and surgical. Ninety-five percent of the cases with complete obstruction required a surgical approach (with or without corticosteroids).
Fig. 1 Flowchart of the literature search process. The case of an Italian boy reported twice $[3,18]$ in the literature was considered only once

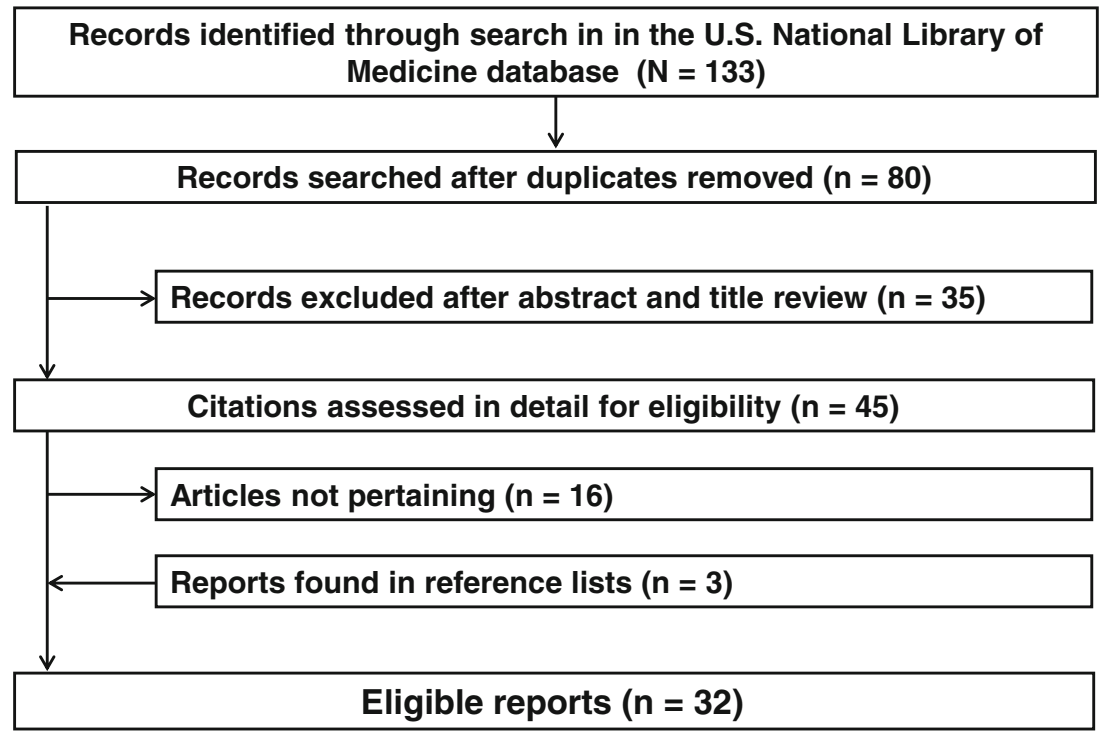




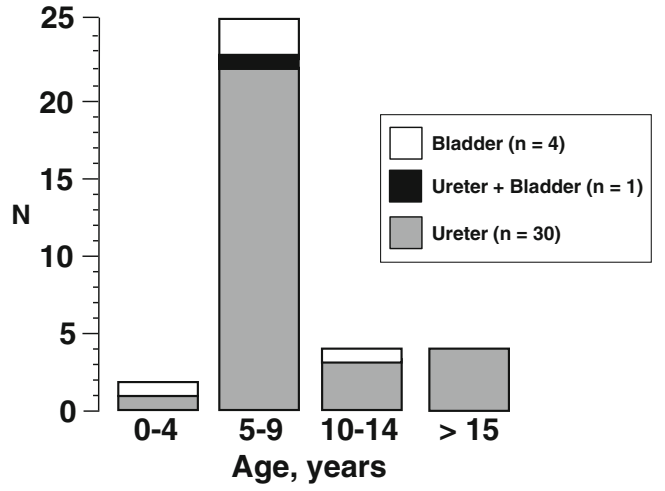

Fig. 2 Age distribution in 35 Henoch-Schönlein patients (24 male and 11 female subjects) with ureteral or vesical involvement

However, the majority of the cases (54\%) with partial obstruction were managed expectantly or medically.

The course was spontaneously favorable in 3 out of 6 partially obstructed ureters $(50 \%$; including a boy with ureteral rupture [10]). Twenty-one ureters were treated with corticosteroids: the course was favorable in 10 and unfavorable in the remaining 11 ureters. Three initially expectantly managed ureters, 11 initially with corticosteroid managed ureters, and the remaining 17 ureters were approached surgically (with or without concurrent drug management with corticosteroids).

The surgical approach, which was mostly preceded by a pyelostomy, included: (1) Nephrectomy in 2 patients with unilateral proximal obstruction and very poor ipsilateral kidney function; (2) Insertion of a stent into the obstructed ureter in 2 cases; (3) Ileal ureteral replacement in 12 cases; (4) Pyeloplasty in the remaining ureters.

Stent insertion, ureteral replacement, and pyeloplasty were reported to be successful in all cases.

The course was similar in 19 patients with mild (surgery required in 19 ureters) and in 11 with severe (surgery required in 12 ureters) Henoch-Schönlein syndrome.

Ureteral specimens, examined histologically in 10 cases, disclosed fibrosis and chronic inflammation. Characteristic vasculitic findings were noted in 5 cases (a

Table 1 Ureteral obstruction in 31 patients $(23$ male and 8 female subjects) affected by Henoch-Schönlein syndrome. The ureteral obstruction was unilateral in 16 and bilateral in 15 patients. The difference between male and female subjects was not significant

\begin{tabular}{llllllll}
\hline & \multicolumn{2}{l}{ Right ureter $(n)$} & & & \multicolumn{2}{l}{ Left ureter $(n)$} \\
\cline { 2 - 3 } \cline { 6 - 8 } & All & Female & Male & & All & Female & Male \\
\hline Proximal & 14 & 4 & 10 & & 19 & 4 & 15 \\
Middle & 2 & 1 & 1 & & 3 & 1 & 2 \\
Distal & 5 & 2 & 3 & & $4^{\text {a }}$ & 1 & 3 \\
\hline
\end{tabular}

${ }^{\text {a }}$ Late obstruction of the left distal ureter developed in a 21-year-old man initially presenting with obstruction of the ipsilateral proximal ureter [24]
Table 2 Initial therapeutic intervention in Henoch-Schönlein patients with partial or complete ureteral obstruction

\begin{tabular}{lll}
\hline & $\begin{array}{l}\text { Partial obstruction } \\
(n=28)\end{array}$ & $\begin{array}{l}\text { Complete obstruction } \\
(n=19)\end{array}$ \\
\hline Expectative & 6 & 0 \\
Corticosteroids alone & 9 & 1 \\
Surgery alone & 7 & 10 \\
Corticosteroids and surgery & 6 & 8 \\
\hline
\end{tabular}

direct immunofluorescence study, performed in 2 children, disclosed depositions of immunoglobulin A).

Vesical involvement

The 5 patients with vesical involvement presented with gross hematuria. Acute urinary retention and a urinary tract infection were also noted in one case. Diagnostic imaging, sometimes associated with a cystoscopy, disclosed diffuse mucosal thickening of the bladder. In one case a blood clot obstructing the bladder outlet and a large intramural hematoma were also noted. The management was expectative (without corticosteroids). A bladder catheter was inserted in the patient with urinary retention secondary to a large blood clot [32]. A biopsy of the bladder mucosa to support the diagnosis was never performed.

\section{Discussion}

The long-term prognosis of Henoch-Schönlein syndrome is nearly totally attributable to kidney disease [1]. The present review complements the results of a preliminary review of the literature published 5 years ago [26]. It confirms that ureteral or vesical involvement, whose occurrence has never been analyzed quantitatively, is very rare, but, if present, is associated with substantial morbidity. Furthermore, the review substantiates the belief that ureteral or vesical involvement is the consequence of vasculitic lesions. Finally, the analysis suggests that Henoch-Schönlein syndrome with ureteral or vesical involvement, like the classical form of Henoch-Schönlein syndrome, might be found in all age groups, but occurs most often between the ages of 5 and 9 years with a male to female ratio of approximately 2:1 [1]. The discussion focuses on the presentation and the management of Henoch-Schönlein syndrome with ureteral involvement.

In Henoch-Schönlein syndrome, ureteritis, like in other systemic vasculitides, characteristically causes luminal obliteration (owing to wall inflammation or to bleeding with clot formation) or, more rarely, ureteral rupture [34-36]. HenochSchönlein ureteritis is likely underappreciated (and its diagnosis delayed) because it occurs rarely and, more importantly, 
because its clinical symptoms, namely colicky abdominal pain and gross hematuria, are mostly attributed to intestinal or renal disease. On the other hand, some reported cases of proximal ureteral obstruction might actually be a congenital ureteropelvic junction obstruction that is unrelated to this vasculitis syndrome. Although in Henoch-Schönlein patients abdominal pain is almost always caused by submucosal or subserosal bleeding and swelling within the intestine, abdominal ultrasound examination is currently often performed to exclude intussusception [1]. Combining abdominal with renal tract ultrasound is a rather simple and non-invasive tool that would likely prevent a delayed diagnosis of ureteral obstruction. This diagnostic technique appears warranted at least in patients with abdominal pain and hematuria. The diagnosis of ureteral stenosis, which is suspected on ultrasound, currently deserves confirmation either by scintigraphy or by magnetic resonance urography. Compared with scintigraphy, magnetic resonance urography could have the potential to provide equivalent information about renal function, but superior information regarding morphology [37].

Controlled trials are not realistic with rare and heterogeneous conditions such as ureteral and vesical involvement in Henoch-Schönlein syndrome. With these limitations in mind, the data of the present analysis prompt us to shortly address both medical and surgical management of ureteral involvement. Corticosteroids in the acute phase of Henoch-Schönlein syndrome do alleviate and treat extra-renal symptoms [38, 39], but these studies, like the present review, do not give data on their efficacy on ureteral (or vesical) involvement. Controversy has remained as to whether corticosteroids can prevent the development of kidney disease and reduce its severity [40], but recent data suggest that early corticosteroid treatment does not prevent kidney disease [41, 42]. Since stenosing ureteritis is self-limited in some instances (and occasionally [43] ameliorates on corticosteroids), surgery other than pyelostomy deserves consideration in patients with persisting ureteral stenosis or a rather low disease activity. Traditional operative reconstruction has been mostly used. Balloon dilatation or stenting, which have been recently used in kidney transplant recipients affected by ureteral stenosis, may be a further option $[44,45]$.

\section{Conclusions}

This review confirms that ureteral or vesical involvement is very unusual and likely underappreciated in HenochSchönlein syndrome. Improved recognition and wider appreciation of ureteral and vesical involvement could help avoid the substantial associated morbidity. The management must be individualized for each patient. A multidisciplinary approach may be of value in planning medical treatment, surgical intervention, and follow-up.

\section{References}

1. Saulsbury FT (2010) Henoch-Schönlein purpura. Curr Opin Rheumatol 22:598-602

2. Balmelli C, Laux-End R, Di Rocco D, Carvajal-Busslinger MI, Bianchetti MG (1996) Purpura Schönlein-Henoch: Verlauf bei 139 Kindern. Schweiz Med Wochenschr 126:293-298

3. Beluffi G, Fiori P, Pricca P, Ravelli A, Martini A (1985) Ureterite stenosante transitoria dell'infanzia - Rara complicanza della porpora reumatoide. Radiol Med (Torino) 71:602-605

4. Bosio M, Ravelli A, Ruperto N, Migliori C, Perotti F, Scotta MS, Martini A (1993) Sindrome di Schönlein-Henoch con severo interessamento sistemico. Minerva Pediatr 45:197-201

5. Bruce RG, Bishof NA, Jackson EC, Skinker DM, McRoberts JW (1997) Bilateral ureteral obstruction associated with HenochSchönlein purpura. Pediatr Nephrol 11:347-349

6. Derot M, Bagros P, Marcel J, Roudier R (1963) À propos de la périurétérite sténosante. Gaz Méd Fr 70:2495-2502

7. García Mérida M, Quiñonero Díaz A, Bueno Fernández A, Galiano Duro E, López Pérez GA, Miguélez Lago C (1989) Estenosis pieloureteral secundaria a purpura de Schönlein-Henoch. Actas Urol Esp 13:118-120

8. Goldis G, Hoeffel JC, Galloy MA, Demiscault G, Bretagne MC (1991) L'imagerie dans les complications du purpura rhumatoïde. Med Infant (Paris) 6:419-426

9. Grasso E, Bianchi GP, Candeo G, Sticca M (1988) Su un caso di ureterite stenosante in porpora di Schönlein-Henoch. Pediatr Med Chir 10:319-321

10. Grotte G, Gierup J, Olsen L (1977) Pyeloureteric obstruction causing anuria in Henoch-Schönlein syndrome: report of a case. Z Kinderchir 20:185-190

11. Hayat P, Sonsino E, Bompard Y, Stora-Castaing N, Weisgerber G (1978) Sténose ischémique de l'uretère au cours du purpura rhumatoïde. Nouv Presse Med 7:3913-3920

12. Ihoriya C, Morita Y, Tokura T, Kidokoro K, Komai N, Sasaki T, Kashihara N (2008) Bilateral ureteral stenosis as a complication of Henoch-Schönlein vasculitis. Mod Rheumatol 18:422-424

13. Junquera JM, Rodríquez-Vigil E, Roza M, Miguel MA, Galbe M, González-Abascal R, Lorenzo J (1978) Estenosis ureteral bilateral "alternante" en el curso de un Schönlein-Henoch. Actas Urol Esp 2:89-90

14. Kano K, Ozawa T, Kuwashima S, Ito S (1998) Uncommon multisystemic involvement in a case of Henoch-Schönlein purpura. Acta Paediatr Jpn 40:159-161

15. Kher KK, Sheth KJ, Makker SP (1983) Stenosing ureteritis in Henoch-Schönlein purpura. J Urol 129:1040-1042

16. Kurunczi S, Gorke WD, Sperling G (1990) Stenosierende Ureteritis und Factor-XIII-Mangel bei anaphylaktoider Purpura. Z Kinderchir 45:314-316

17. Maherzi A, Kaabar N, Boussetta K, Salem M, Hammou A, Chaouachi B, Bousnina S (1997) Urétérite sténosante bilatérale au décours du purpura rhumatoïde de Henoch-Schönlein. Arch Pediatr 4:36-39

18. Martini A, Ravelli A, Beluffi G (1986) Urinary microscopy in the diagnosis of haematuria in Schönlein-Henoch purpura. Eur J Pediatr 144:591-593

19. Mitrofanoff P (1977) Urétérite sténosante et purpura rhumatoïde. A propos d'un cas traité par remplacement bilatéral total des uretères par un greffon iléal. Ann Chir Infant 18:343-356

20. Mougenot B, Mitrofanoff P, Bouissou F, Doré F, Fauré C (1978) Stenosing ureteritis during Henoch-Schönlein purpura in children. Ann Radiol (Paris) 21:215-222

21. Moyano MJ, Alvarez J, Millán A, Amor J (2006) Ureteritis en el contexto de una púrpura de Schönlein-Henoch. Nefrología 26:623-625

22. Pfister C, Liard-Zmuda A, Dacher J, Dubois D, Grise P, Mitrofanoff $P(2000)$ Total bilateral ureteral replacement for stenosing ureteritis in Henoch-Schönlein purpura. Eur Urol 38:96-99 
23. Piot M, Gout JP, Baudain P, Faure G, Bost M (1981) Urétérohydronéphrose au cours d'un purpura rhumatoïde: urétérite sténosante? Pediatrie 36:277-281

24. Powell JM, Ware H, Williams G (1987) Recurrent ureteric obstruction in association with Henoch-Schönlein purpura. Postgrad Med J 63:699-701

25. Robson WL, Leung AK, Mathers MS (1994) Renal colic due to Henoch-Schönlein purpura. J S C Med Assoc 90:592-595

26. Siomou E, Serbis A, Salakos C, Papadopoulou F, Stefanidis CJ, Siamopoulou A (2008) Masked severe stenosing ureteritis: a rare complication of Henoch-Schönlein purpura. Pediatr Nephrol 23:821825

27. Smet MH, Marchal G, Oyen R, Breysem L (1991) Stenosing hemorrhagic ureteritis in a child with Henoch-Schönlein purpura: CT appearance. J Comput Assist Tomogr 15:326-328

28. Thompson JS, McAlister WH (1975) Subepithelial hemorrhage in the renal pelvis and ureter simulating pyeloureteritis cystica. Pediatr Radiol 13:156-157

29. MacPherson RI (1974) The radiologic manifestations of HenochSchönlein purpura. J Can Assoc Radiol 25:275-281

30. Allen SJ, Sprigg A, Davidson DC (1992) Haemorrhagic cystitis and urinary retention in Henoch-Schönlein purpura. Eur J Pediatr 151: 312

31. Pery M, Alon U, Lachter JH, Kaftori JK, Gaitini D, Rosenberger A (1990) The value of ultrasound in Schoenlein-Henoch purpura. Eur J Pediatr 150:92-94

32. Jašić M, Subat-Dezulović M, Nikolić H, Jonjić N, Manestar K, Dezulović M (2011) Henoch-Schönlein purpura complicated by appendicitis, intussusception and ureteritis. Coll Antropol 35:197201

33. Corbett ST, Lennington JN, Chua AN, Gonzales ET Jr (2010) Stenosing ureteritis in a 7-year-old boy with Henoch-Schönlein purpura nephritis: a case report and review of the literature. J Pediatr Urol 6:538-542

34. Pereira RM, Daud RM, Messina WC, Oliveira RM, Cossermelli W (1992) Stenosing ureteritis in a child with necrotizing vasculitis. Clin Rheumatol 11:112-115
35. Kamar N, Malavaud B, Alric L, le Mao G, Mazerolles C, Duffaut M, Sarramon JP, Pourrat J (2003) Ureteral stenosis as the sole manifestation of Wegener's granulomatosis. Urology 62:352

36. Baskin L, Mee S, Matthay M, Carroll PR (1989) Ureteral obstruction caused by vasculitis. J Urol 141:933-935

37. Cerwinka WH, Kirsch AJ (2010) Magnetic resonance urography in pediatric urology. Curr Opin Urol 20:323-329

38. Ronkainen J, Koskimies O, Ala-Houhala M, Antikainen M, Merenmies J, Rajantie J, Ormälä T, Turtinen J, Nuutinen M (2006) Early prednisone therapy in Henoch-Schönlein purpura: a randomized, double-blind, placebo-controlled trial. J Pediatr 149:241-247

39. Jauhola O, Ronkainen J, Koskimies O, Ala-Houhala M, Arikoski P, Hölttä T, Jahnukainen T, Rajantie J, Ormälä T, Nuutinen M (2010) Clinical course of extrarenal symptoms in Henoch-Schonlein purpura: a 6-month prospective study. Arch Dis Child 95:871-876

40. Chartapisak W, Opastiraku S, Willis NS, Craig JC, Hodson EM (2009) Prevention and treatment of renal disease in HenochSchönlein purpura: a systematic review. Arch Dis Child 94:132-137

41. Jauhola O, Ronkainen J, Koskimies O, Ala-Houhala M, Arikoski P, Hölttä T, Jahnukainen T, Rajantie J, Ormälä T, Turtinen J, Nuutinen M (2010) Renal manifestations of Henoch-Schonlein purpura in a 6month prospective study of 223 children. Arch Dis Child 95:877-882

42. Dudley J, Smith G, Llewelyn-Edwards A, Bayliss K, Pike K, Tizard J (2013) Randomised, double-blind, placebo-controlled trial to determine whether steroids reduce the incidence and severity of nephropathy in Henoch-Schonlein Purpura (HSP). Arch Dis Child. doi:10. 1136/archdischild-2013-303642

43. Atsuta T, Shimizu Y, Masuda N, Watanabe J, Sumiyoshi S, Yoshimura K, Kanematsu A, Ogawa O (2012) First report of idiopathic segmental ureteritis successfully treated by steroid therapy. Int J Urol 19:583-586

44. Juaneda B, Alcaraz A, Bujons A, Guirado L, Díaz JM, Martí J, de la Torre P, Sabaté S, Villavicencio H (2005) Endourological management is better in early-onset ureteral stenosis in kidney transplantation. Transplant Proc 37:3825-3827

45. Adamo R, Saad WE, Brown DB (2009) Percutaneous ureteral interventions. Tech Vasc Interv Radiol 12:205-215 